Research Article

Araştırma Makalesi

DOI: $10.24011 /$ barofd.447207
Bartın Orman Fakultesi Dergisi,

21 (1): 129-135,

15 Nisan/April, 2019
Journal of Bartin Faculty of Forestry

p-ISSN :1302-0943

e-ISSN :1308-5875

\title{
Kraft Yöntemiyle Aynı Pişirme Şartlarında Sarıçam ve Titrek kavak Odunu Yongalarından Elde Edilen Kâğıt Hamurunun Verimi ve Kâğıt Özelliklerinin Karşılaştırılması
}

\author{
Fadime YURDAKURBAN ${ }^{1}$, Ayhan GENÇER*1 \\ ${ }^{1}$ Bartın Üniversitesi, Orman Fakültesi, Orman Endüstri Mühendisliği Bölümü,74100, BARTIN
}

\section{Öz}

Bu çalışmada, sarıçam (Pinus sylvestris L.) ve titrek kavak (Populus tremula L.) odunundan Sülfat (Kraft) yöntemiyle aynı koşullarda kâğıt hamuru ve deneme kâğıtları üretilmiştir. Literatür araştırması yapılıp, yonga/çözelti oranı $1 / 4$, pişirme sıcaklığı $170 \pm 2{ }^{\circ} \mathrm{C}$, maksimum sıcaklığa ulaşma süresi 90 ve maksimum sıcaklıkta pişirme süresi 75 dakika sabit alınarak; Sülfat (Kraft) yöntemi ile aktif alkali/sülfitide oranı 18/25 oranında pişirmeler yapılmıştır. Elde edilen kağıt hamuru ve kâğıtların bazı özelliklerinde önemli farkların ortaya çıktığı sonucuna varılmıştır. Özellikle, titrek kavak odunundan elde edilen kağıt hamurunun elenmiş veriminin $(\% 53,72)$ sarıçam odunundan elde edilen kağıt hamurundan $(\% 42,015)$ yüksek olduğu tespit edilmiştir.

Anahtar Kelimeler: Pinus sylvestris L. odunu; Populus tremula L. odunu; kraft kâğıt hamuru üretimi; hamur verimi

\section{Comparison of Pulp Yield and Handsheet Properties of Scots Pine and European Aspen Wood under Exact Pulping Conditions Using Kraft Method}

\begin{abstract}
In this study, pulp and handsheets were produced using Sulfate (Kraft) method from Scots Pine (Pinus sylvestris L.) and European Aspen (Populus tremula L.) wood under the same cooking conditions. According to literature research, it the chip/liquor ratio was used as $1 / 4$, the cooking temperature as $170 \pm 2{ }^{\circ} \mathrm{C}$ and the reaching time to maximum temperature as 90 and cooking time at maximum cooking temperature as 75 minutes. The ratio of active alkali/sulfidity was chosen as $18 / 25$. As a result, significant differences in some properties of pulp and test papers have been observed. In particular, it is seen that the pulp yield obtained from the European aspen wood (53.72\%) was found higher than that of the pulp yield (42.01\%) obtained from the Scots pine.
\end{abstract}

Keywords: Pinus sylvestris (L.) wood; Populus tremula (L.) wood; Kraft method; pulp yield 


\section{Giriş}

Mevcut kağıt kimyasal hamuru üretim yöntemleri arasında en çok kullanılanı kraft yöntemidir. Bu yöntemin tüm ağaç türlerinden kağıt hamuru üretimine uygun olduğu bilinmektedir. Kağıt hamuru pişirme sırasında pişirme çözeltisinin oduna nüfuz etme yeteneği ve delignifikasyon oranı o ağacın anatomik yapısı ve kimyasal özellikleri ile doğrudan orantılıdır. Bu özellikler ağaç türlerine göre değişiklik gösterebilmektedir. Özellikle yapraklı ağaç ve iğne yapraklı ağaç türleri arasında önemli farklılıklar görülmektedir.

$\mathrm{Bu}$ çalışmada ülkemizde yaygın olarak bulunan titrek kavak (TK) ve sarıçam (SÇ) kullanılmıştır. SÇ kuzeyde İskoçya'dan Sibirya steplerine, güneyde İspanya'dan Anadolu'da 38³4' kuzey enlemine uzanan geniş bir yayılım göstermektedir. TK tüm Avrupa, Kuzey Afrika, Orta Doğu, Kafkasya, Sibirya, Japonya ve Türkiye'de step dişında kalan (Anşin ve Özkan, 1993), odunu kirli beyaz renkte hafif ve yumuşak (Aytuğ, 1984) dağınık traheli özellik gösteren bir ağaç türüdür (Göker, 1983).

Çalışmada kullanılan SÇ ve TK odununun lif morfolojik özellikleri belirlenmiş ve kimyasal analizleri yapılmıştır. Kâğıt hamuru üretiminde Kraft (sülfat) yöntemi ile aynı koşullarda kâğıt hamuru ve deneme kâğıtları üretilerek elde edilen hamur ve kâğıdın bazı özellikleri karşılaştırılmıştır.

\section{Materyal ve Metot}

Bu çalışmada deney materyali Bartın Bölgesi’nden temin edilmiştir. Odunların yongalama işlemi el aletleri yardımı ile yapılmıştır. Liflerin maserasyonunda klorit yöntemi kullanılmıştır (Wise ve Jahn 1952). Maserasyondan elde edilen liflerden kalıcı preparatlar hazırlanmış ve sşık mikroskobunda 40 adet trahe hücresi boyu, 308 adet lif boyu, 108 adet lif ve lümen genişliği ölçülmüştür. Lif genişliğinden lümen genişliği çıkartılıp ikiye bölünerek çeper kalınlığı bulunmuştur. Lif boyut ilişkileri aşağıdaki eşitliklerden hesaplanmıştır.

Elastiklik oranı $=$ (Lümen Çapı $\quad \mathrm{x} \quad$ 100) / Lif $\quad$ Genişliği

(1)

Runkel sınıflandırması $=($ Lif çeper Kalınlığ 1 x 2) / Lümen Çapı

Keçeleşme oranı $=$ Lif Uzunluğu / Lif Genişliği

Katılık katsayısı $=($ Lif Çeper Kalınlığı x 100) / Lif Genişliği

\subsection{Kimyasal Analizlere Ait Yöntemler}

TK ve SÇ yongalarının rutubeti belirlenerek kimyasal analiz numuneleri hazırlanmıştır (TAPPI T 264). SÇ ve TK odununun kimyasal özellikleri belirlenirken Tablo 1'de gösterilen yöntemler kullanılmıştır.

Tablo 1. Kimyasal analiz ve kâğıtların bazı fiziksel, optik ve mekanik testlerinde kullanılan yöntemler.

\begin{tabular}{ll}
\hline Deney & Kullanılan Yöntem \\
\hline Holoselüloz tayini & Klorit (Wise ve Jahn, 1952) \\
Alfa selüloz tayini & Rowell vd. 2005 \\
Lignin tayini & TAPPI T 222 om-02 \\
Kül tayini & ASTM Standart D 1102-84 \\
Sicak ve soğuk su çözünürlüğü & TAPPI T 207 cm-99 \\
$\% 1$ NaOH çözünürlüğü & TAPPI T 212 om-02 \\
Kalınlık & TAPPI T 411 om-97 \\
Hava geçirgenliği & ISO 5636-3 \\
Opaklık & TAPPI T 519 om-02 \\
Parlaklık & TAPPI T 525 om-02 \\
Yrtılma indisi & TAPPI T 414 om-98 \\
Kopma indisi & TAPPI T 494 om-01 \\
Patlama indisi & TAPPI T 403 om-02 \\
\hline
\end{tabular}




\subsection{Sülfat (Kraft) Yöntemi}

Atik (2001) TK'dan, Gülsoy ve Eroğlu (2011) karaçamdan, İstek ve Gönteki (2009) sahil çamınından, Kraft yöntemi ile kâğıt hamuru üretiminde pişirme sıcaklığının $170{ }^{\circ} \mathrm{C}$ olduğunu bildirmişlerdir. Gülsoy vd. (2015) nar (Punica granatum L.) odunundan kraft yöntemi ile kağıt hamuru üretiminde pişirme sıcaklığının $170{ }^{\circ} \mathrm{C}$ ve maksimum sıcaklığa ulaşma süresi: 90 dak., maksimum sıcaklıkta pişirme süresi: 75 dak. olarak belirtmiştir. $\mathrm{Bu}$ nedenlerle SÇ ve TK yogaları Kraft yöntemi ile yonga/ çözelti oranı :4/1, NaOH: \%18, $\mathrm{Na}_{2} \mathrm{~S}: \% 25$, maksimum sıcaklık: $170^{\circ} \mathrm{C}$, maksimum sıcaklığa ulaşma süresi: 90 dak., maksimum sicaklıkta pişirme süresi: 75 dak. koşullarında kağıt hamuru elde edilmiştir. Pişirme sonucunda elde edilen hamurlar TAPPI T 275 sp-02 standardına göre Somerville tipi sarsıntılı vakum eleğinde elenerek elek artığı ayrılmıştır. Elenen hamurda verim ve elek artığ 1 miktarı \% olarak hesaplanmıştır. Elenen hamurlar TAPPI T 200 sp-01 standardına göre Hollander'de $25^{\circ}$ SR'e kadar dövülmüştür. Hamurların serbestlik derecesi Schopper Riegler cihazında ISO 5267 1 standardına göre belirlenmiştir. Dövülmemiş, $25^{\circ} \mathrm{SR}$ kadar dövülmüş hamurlardan ISO 5269-2 standardına göre $75 \pm 2 \mathrm{~g} / \mathrm{m}^{2}$ gramajlı 10 'ar adet deneme kâğıtları yapılmıştır. Elde edilen kâğıt hamurlarının kappa numarası ve viskozite belirlenmesinde sırasıyla TAPPI T 236 om-99 ve SCAN-CM 15-62 standartları kullanılmıştır.

\subsection{Kâğıtların Bazı Fiziksel, Optik ve Mekanik Özellikleri}

Deneme kâğıtları TAPPI T 402 sp-03 standardına göre kondisyonlandıktan sonra Tablo 1'de gösterilen standartlara göre bazı fiziksel, optik ve mekanik özellikleri belirlenmiştir.

\subsection{Verilerin Değerlendirilmesi}

$\mathrm{Bu}$ çalışmada elde edilen verilerin değerlendirilmesinde SPSS 16.0 paket programı kullanılmıştır. Bu program kullanılarak deneme kâğıtlarının özelliklerinin T analizi yapılmıştır. Microsoft Office 2010 paket programı kullanılarak aritmetik ortalaması ve standart sapma belirlenmiştir.

\section{Bulgular ve Tartışma}

SÇ ve TK odunlarına ait lif boyutlarının karşılaştırılması Tablo 2'de verilmiştir.

Tablo 2. SÇ ve TK odunlarına ait lif boyutlarının karşılaștırılması.

\begin{tabular}{lccccc}
\hline & $\begin{array}{c}\text { Lif Uzunluğu } \\
(\mathrm{mm})\end{array}$ & $\begin{array}{c}\text { Lif } \\
\text { Genişliği } \\
(\mu \mathrm{m})\end{array}$ & $\begin{array}{c}\text { Lümen } \\
\text { Genişliği } \\
(\mu \mathrm{m})\end{array}$ & $\begin{array}{c}\text { Çeper } \\
\text { Kalılı̆̆ } \\
(\mu \mathrm{m})\end{array}$ & $\begin{array}{c}\text { Trahe } \\
\text { Uzunluğu } \\
(\mu \mathrm{m})\end{array}$ \\
\hline SÇ (Tespit $)$ & 3,20 & 33,30 & 15,35 & 10,68 & - \\
SÇ (Alkan,2004) & 4,01 & 49,00 & 34,80 & 7,10 & - \\
SÇ (Köksal ve K1lıç & 3,10 & 40,90 & 28,30 & 9,90 & - \\
Pekgözlü, 2016) & 1,46 & 20,66 & 9,56 & 5,05 & 755,3 \\
TK (Tespit) & 0,85 & 15,10 & 6,20 & 4,50 & - \\
$\begin{array}{l}\text { Olea europea (L). } \\
\text { (Ververis vd. 2004) }\end{array}$ & 1,58 & 35,97 & 22,30 & 6,84 & - \\
$\begin{array}{l}\text { Actinidia deliciosa } \\
\text { (Yaman ve Gençer, 2005) }\end{array}$ & & & & & \\
\hline
\end{tabular}

Tablo 2 incelendiğinde $\mathrm{SÇ}$ odununun lif uzunluğu $3,20 \mathrm{~mm}$, lif genişliği 33,30 $\mu \mathrm{m}$, lümen genişliği $15,35 \mu \mathrm{m}$, çeper kalınlığ 10,68 $\mu \mathrm{m}$ olarak bulunmuştur. Alkan (2004), yaptığ çalışmada SÇ odununun lif uzunluğu 4,01 $\mathrm{mm}$, lif genişliği 49,00 $\mu \mathrm{m}$, lümen genişliği $34,80 \mu \mathrm{m}$, lif çeper kalınlığ 1 ise 7,10 $\mu \mathrm{m}$ olarak tespit edilmiştir. Bu çalışmadan elde edilen sonuçlar Alkan (2004)'ün sonuçları ile benzerlik göstermektedir. Köksal ve Kılıç Pekgözlü (2016), yaptıkları çalışmada SÇ ortalama lif uzunluğu 3,10 mm, lif genişliği 40,90 $\mu \mathrm{m}$, lümen genişliği $28,30 \mu \mathrm{m}$, lif çeper kalınlığ $9,90 \mu \mathrm{m}$ olduğu tespit etmiştir.

Tablo 2 incelendiğinde TK odunun lif uzunluğu 1,46 mm, lif genişliği 20,66 $\mu \mathrm{m}$, lümen genişliği 9,56 $\mu \mathrm{m}$, çeper kalınlığ $5,05 \mu \mathrm{m}$, trahe uzunluğu 755,3 um olarak bulunmuştur. Ververis vd. (2004) yaptığ 1 çalışmada Olea europea (L).odununun lif uzunluğu $850 \mu \mathrm{m}$, lif genişliği $15,1 \mu \mathrm{m}$, lümen genişliği $6,2 \mu \mathrm{m}$, çeper kalınlı̆̆ 4,5 $\mu \mathrm{m}$ olduğu tespit edilmiştir. Bu çalışmada elde edilen sonuçlarda titrek kavak odununun lif uzunluğunun ve çeper kalınlığının daha fazla olduğu görülmüştür. 
Yaman ve Gençer (2005), yaptıkları çalışmada Actinidia deliciosa (L.) odunun lif uzunluğu 1,58 mm, lif genişliği 35,97 $\mu \mathrm{m}$, lümen genişliği 22,30 $\mu \mathrm{m}$, çeper kalınlığı 6,84 $\mu \mathrm{m}$ olduğu tespit edilmiştir. Bu çalışmada elde edilen sonuçlara göre TK odununun lümen genişliğinin ve çeper kalınlığının daha az olduğu görülmüştür.

\subsection{Sarıçam ve Titrek Kavak Liflerinin Morfolojik Özelliklerinin Kâğıdın Bazı Fiziksel ve Mekanik Özellikleri Üzerine Etkisi}

SÇ ve TK odununa ait lif boyutları arasındaki ilişki Tablo 3'de verilmiştir.

Tablo 3. SÇ ve TK odunlarına ait lif boyutları arasındaki ilişkiler ve karşılaştırılması.

\begin{tabular}{ccccc}
\hline Türler & $\begin{array}{c}\text { Elastiklik } \\
\text { Katsayısı }\end{array}$ & $\begin{array}{c}\text { Rijidite } \\
\text { Katsayıs }\end{array}$ & Runkel Oranı & $\begin{array}{c}\text { Keçeleşme } \\
\text { Oranı }\end{array}$ \\
\hline SÇ (Tespit) & 46,09 & 51,11 & 1,39 & 99,85 \\
SÇ (Alkan, 2004) & 71,02 & - & 0,40 & 81,91 \\
TK (Tespit) & 46,27 & 48,88 & 2,11 & 70,76 \\
Actinidia deliciosa & 61,99 & 19,00 & 0,61 & 44,03 \\
\hline
\end{tabular}

Tablo 3'deki SÇ odununa ait lif boyutlarından türetilen değerler incelendiğinde elastiklik katsayısı 46,09, rijitide katsayısı 51,11, Runkel oranı 1,39, keçeleşme oranı 99,85 olarak tespit edilmiştir. Alkan (2004), göre elastiklik katsayıs1 71,02, Runkel oranı 0,40, keçeleşme oranı 81,91 olarak bulmuştur. Bu çalışmadaki değerlere göre SÇ odununun elastiklik katsayı oranının daha düşük olduğu ve Runkel oranının da daha yüksek olduğu belirlenmiştir.

Tablo 3'deki TK odununa ait lif boyutlarından türetilen değerler incelendiğinde elastiklik katsayısı 46,27, rijitide katsayıs1 48,88, Runkel oranı 2,11, keçeleşme oranı 70,76 olarak tespit edilmiştir. Yaman ve Gençer (2005), yaptıkları çalışmada Actinidia deliciosa (L.) odununun elastiklik katsayısı 61,99, rijitide katsayısı 19,00, Runkel oranı 0,61, keçeleşme oranı 44,03, olarak bulmuştur. Tespit edilen elastiklik katsayısının Actinidia deliciosa (L.) odunundan daha düşük olduğu, keçeleşme oranı, rijitide katsayısı ve Runkel oranının Actinidia deliciosa (L.) odunundan daha yüksek olduğu belirlenmiştir.

Tablo 3'deki SÇ odununa ait lif boyutlarında türetilen değerleri incelendiğinde elastikik katsayısı 46,09'dur. Tablo 3'deki TK odununa ait lif boyutlarında türetilen değerleri incelendiğinde elastiklik katsayısı 46,27'dir. Elastiklik katsayısı 30-50 arasında olan lifler çeperleri kalın, lümenleri dar olduğundan zayıf kâğıtlar verir. SÇ odununun rijitide katsayı 51,11 , TK odunun rijitide oran1 48,88 olarak tespit edilmiştir. Rijitide katsayısı ise elastiklik katsayısının tersi bir durum oluşmaktadır. Rijitide katsayısının yüksek olan liflerden üretilen kâğıdın fiziksel direnç özellikleri olumsuz etkilemekte ve katılık katsayısı yüksek olan liflerde lifler arası bağlantı yeterince kurulamamaktadır (Yaman ve Gençer, 2005). Rijitide katsayısının büyüklüğü, kâğıdın fiziksel direnç niteliklerinin, özellikle de patlama ve kopma dirençlerinin düşük olacağı anlamını taşır. SÇ odunun Runkel oranı 1,39, TK odununun Runkel oranı 2,11 olarak tespit edilmiştir. Runkel oranı 1'den büyük ise kalın çeperli lifleri gösterir (Eroğlu, 2003). SÇ odunun keçeleşme oranı 99,85, TK odunun keçeleşme oranı 70,76 olarak tespit edilmiştir. Keçeleşme oranı lif uzunluğu/lif genişliği şeklinde ifade edildiğinden lif uzunluğu orantıyı olumlu yönde etkilediğinden uzun liflere sahip hammaddelerden elde edilecek kâğıtların keçeleşmelerinin daha iyi olacağı açıktır. SÇ ve TK odunlarına ait bazı fiziksel ve kimyasal özelliklerine ait bulgular ve karşılaştırılması Tablo 4'de verilmiştir.

Tablo 4. SÇ ve TK odunlarının bazı fiziksel ve kimyasal özelliklerine ait bulgular.

\begin{tabular}{lcccccc}
\hline $\begin{array}{l}\text { Özellikler } \\
(\%)\end{array}$ & $\begin{array}{c}\text { SÇ } \\
\text { (Tespit) }\end{array}$ & $\begin{array}{c}\text { SÇ } \\
\text { (Dönmez } \\
\text {, 2010) }\end{array}$ & $\begin{array}{c}\text { SÇ } \\
\text { (Kılıç vd. } \\
2010)\end{array}$ & $\begin{array}{c}\text { TK } \\
\text { (Tespit) }\end{array}$ & $\begin{array}{c}\text { TK } \\
\text { (Gulsoy ve } \\
\text { Tufek, 2013) }\end{array}$ & $\begin{array}{c}\text { TK } \\
\text { (Gücüş ve } \\
\text { Eroğlu, 2013 }\end{array}$ \\
\hline $\begin{array}{l}\text { Rutubet } \\
\text { miktarı }\end{array}$ & 10.9 & - & - & 8 & - & \\
Holoselüloz & $70.66 \pm$ & 65.75 & 71,37 & $80,47 \pm 0,8$ & 82,68 & 85,70 \\
$\alpha$-selüloz & $40.36 \pm$ & 46.27 & 48,58 & $34,96 \pm 1,6$ & 49,03 & - \\
Lignin & $26.41 \pm$ & 27.23 & 27,57 & $12,32 \pm 1,1$ & 16,69 & 17,20 \\
Soğuk su* & $1.88 \pm$ & - & 1,74 & $2,31 \pm 0,12$ & 1,73 & 14,90 \\
Sicak su* & $2.05 \pm$ & 8.45 & 3,11 & $3,71 \pm 0,23$ & 3,04 & 5,90 \\
$\% 1$ NaOH* & $10.66 \pm$ & 10.62 & 12,88 & $16,31 \pm 0,7$ & 15,34 & 19,20 \\
Kül miktarı & $0.45 \pm$ & - & 0,33 & $0,31 \pm 0,07$ & 0,31 & - \\
\hline
\end{tabular}

* çözünürlüğü göstermektedir 
Tablo 4'de SÇ odununun bazı kimyasal özelliklerine ait bulgular SÇ ile yapılmış diğer çalışmalar ile karşılaştırıldığında; SÇ odunu holoselüloz miktarının, Dönmez (2010) SÇ odunundan daha yüksek olduğu ve diğerleri ile yakın değerlerde olduğu tespit edilmiştir. SÇ odunu $\alpha$-selüloz içeriği Dönmez (2010) değerlerine göre daha düşük olduğu tespit edilmiştir. SÇ odunu lignin içeriği Alkan (2004) değerlerine göre yüksek olduğu ve Dönmez (2010)'a göre düşük olduğu tespit edilmiştir. SÇ odununun soğuk su çözünür, sıcak su çözünürlüğü ve \%1 NaOH Çözünürlüğü, Alkan (2004) değerlerine göre daha düşük olduğu, Dönmez (2010)'a göre sıcak su çözünürlüğü daha düşük, \%1 NaOH çözünürlüğü daha yüksek olduğu tespit edilmiştir.

Tablo 4' de TK odunun bazı kimyasal özelliklerine ait bulgular TK ile yapılmış diğer çalışmalar ile karşılaştırıldığında; tespit edilen holoselüloz ve lignin miktarının, Gulsoy ve Tufek (2013) ve Gücüş ve Eroğlu (2013) tarafından elde edilen sonuçlardan daha düşük olduğu, $\alpha$-selüloz miktarının ise Gulsoy ve Tufek (2013) tarafından elde edilen sonuçtan daha düşük olduğu görülmüştür. TK odununun tespit edilen çözünürlük değerleri Gulsoy ve Tufek (2013) tarafindan elde edilen değerlerden daha yüksek, Gücüş ve Eroğlu (2013) tarafindan elde edilen değerlerden daha düşük olduğu belirlenmiştir. TK odununun tespit edilen kül içeriğinin Gulsoy ve Tufek (2013) tarafindan elde edilen ile aynı olduğu tespit edilmiştir.

\subsection{Sarıçam ve Titrek Kavak Odununun Kâğıt Hamuru Ve Deneme Kâğıtlarına Ait Bulguların Değerlendirilmesi}

SÇ ve TK odununun kâğıt hamuru ve deneme kâğıtlarına ait bulguların değerlendirilmesi aşağıdaki gibidir.

Tablo 5. SÇ ve TK odunundan kraft yöntemiyle elde edilen kâğıt hamurlarının özellikleri.

\begin{tabular}{llcccc}
\hline Ağaç Türü & $\begin{array}{c}\text { Elenmiş } \\
\text { Verim }(\%)\end{array}$ & $\begin{array}{c}\text { Elek Artı̆̆ } \\
(\%)\end{array}$ & $\begin{array}{c}\text { Toplam } \\
\text { Verim } \\
(\%)\end{array}$ & Kappa no & $\begin{array}{c}\text { Vizkozite } \\
\left(\mathrm{cm}^{3} / \mathrm{g}\right)\end{array}$ \\
\hline SÇ & 42,01 & 0,10 & 42,11 & $30,43 \pm 1,15$ & $1123 \pm 0,30$ \\
TK & 53,72 & 0,10 & 53,82 & $16,11 \pm 2,65$ & $1203 \pm 0,55$ \\
\hline
\end{tabular}

TK odunundan elde edilen hamurun elenmiş verimi, SÇ odunundan elde edilen hamurdan yüksek olduğu ve Kappa numarasının daha düşük olduğu görülmektedir.

\subsection{Kraft Yöntemiyle Elde Edilen Kâğıt Hamuru Verimlerinin Karşılaştırılması}

SÇ ve TK odunundan Kraft yöntemiyle elde edilen deneme kâğıtlarının bazı fiziksel, optik ve mekanik özellikleri Tablo 6'da verilmiştir.

Tablo 6. SÇ ve TK odunundan Kraft yöntemiyle elde edilen deneme kâğıtlarının bazı fiziksel, optik ve mekanik özellikleri.

\begin{tabular}{|c|c|c|c|c|c|c|c|}
\hline \multirow[b]{2}{*}{$\begin{array}{l}\text { Ağgaç } \\
\text { Türü }\end{array}$} & \multicolumn{2}{|c|}{ Fiziksel özellikler } & \multicolumn{2}{|c|}{ Optik özellikler } & \multicolumn{3}{|c|}{ Mekanik özellikler } \\
\hline & $\begin{array}{c}\text { Kalınlık } \\
(\mu \mathrm{m})\end{array}$ & $\begin{array}{c}\text { Hava } \\
\text { geçirgenliği } \\
(\mathrm{ml} / \mathrm{dk})\end{array}$ & $\begin{array}{c}\text { Opaklık } \\
(\%)\end{array}$ & $\begin{array}{c}\text { Parlaklik } \\
(\%)\end{array}$ & $\begin{array}{l}\text { Yrrtılma } \\
\text { indisi } \\
\left(\mathrm{mN} \cdot \mathrm{m}^{2} / \mathrm{g}\right)\end{array}$ & $\begin{array}{l}\text { Kopma } \\
\text { indisi } \\
\text { (N.m/g) }\end{array}$ & $\begin{array}{c}\text { Patlama } \\
\text { indisi } \\
\left(\mathrm{kPa} \cdot \mathrm{m}^{2} / \mathrm{g}\right)\end{array}$ \\
\hline $\mathrm{SÇ}$ & $\begin{array}{l}113,6 \pm 0, \\
1\end{array}$ & $332,3 \pm 0,4$ & $98,9 \pm 0,4$ & $\begin{array}{l}18,5 \pm 0, \\
1\end{array}$ & $7,8 \pm 0,1$ & $97,7 \pm 0,4$ & $3,7 \pm 0,01$ \\
\hline TK & $\begin{array}{l}102,7 \pm 0 \\
2\end{array}$ & $312,1 \pm 0,3$ & $\begin{array}{l}99,19 \pm 0, \\
2\end{array}$ & $\begin{array}{l}23,9 \pm 0 \\
1\end{array}$ & $3,82 \pm 0,1$ & $74,49 \pm 0,4$ & $2,6 \pm 0,01$ \\
\hline
\end{tabular}

SÇ Kraft kâğıt hamurundan elde edilen kâğıtların mekanik özelliklerinin TK Kraft kâğıt hamurundan elde edilen kâğıtlardan daha yüksek çıkması, SÇ odunu liflerinin TK odunu liflerinden daha uzun olmasından kaynaklamaktadır. TK kâğıt hamurundan elde edilen kâğıtların parlaklık değerinin SÇ kâğıt hamurundan elde edilen kâğıtlardan yüksek ve opaklık değerinin düşük çıkması titrek kavak odunun doğal renginin sarıçam odunundan daha açık olmasından kaynaklanmaktadır.

\section{Sonuç ve Öneriler}

$\mathrm{Bu}$ çalışmada SÇ ve TK yongalarından Kraft yöntemiyle pişirme şartları aynı olacak şekilde iki ayrı pişirme yapılmıştır. Kâğıt hamurlarının kappa numaraları ve viskoziteleri incelendiğinde SÇ kâğıt hamurunun kappa numarası 30,43, TK kâğıt hamurunun ise 16,11 olduğu belirlenmiştir. TK'da kappa numarasının az olması 
hamurda kalan ligninin azaldığını göstermekte olup, beklenen bir sonuçtur. Hamurların viskozite değeri karşılaştırıldığında SÇ kâğıt hamurunun viskozite değerinin TK kâğıt hamurundan daha düşük olduğu belirlenmiştir.

Kâğıt hamurlarından elenmiş verim olarak en yüksek olan TK olduğu, elek artığının en yüksek olduğu SÇ olduğunu ve toplam verim değerlerinin en yüksek olan TK olduğu belirlenmiştir. Bu durum SÇ odunun lignin oranının TK yüksek olmasından kaynaklanabilir. SÇ odunlarından elde edilen hamurların Kappa numarasının yüksek çıkması bunun bir göstergesidir. $\mathrm{Bu}$ durumda $\mathrm{SÇ}$ için pişirme şartları belirlenirken aktif alkali ve sülfidite oranları arttırılarak yeni bir pişirme planı hazırlanması gerektiği kanaatindeyiz.

\section{Kaynaklar}

1. Alkan, Ç. (2004). Türkiye 'nin Önemli Yaprak ve İğne Yapraklı Ağaç Odunlarının Mikrografik Yönden İncelenmesi. Yüksek Mühendislik Tezi (yayımlanmamış), Z.K.Ü. Fen Bilimleri Enstitüsü, Orman Endüstri Mühendisliği Anabilim Dalı, Bartın, 110 s.

2. Anşin, R. ve Özkan, Z.C, (1993). Tohumlu Bitkiler (Spermatophta), Odunsu Taksonlar, K.T.Ü. Orman Fak. Genel Yayın No: 167, Fakülte Yayın No: 19, I.Baskı, K.T.Üniversitesi Basımevi, Trabzon.

3. Atik, C. (2001). Farklı Pişirme Yöntemleri ile Titrek Kavak (Populus tremula L.)' tan Yüksek Verimli Kağıt Hamuru Elde Etme Olanakları, İ.Ü.O.F. Dergisi, 51, 1, 43-51.

4. Aytuğ, B, (1984). Odun Anatomisi, İ.Ü. Orman Fakültesi Roto Bask1, İstanbul, 61-63 s.

5. Dönmez, İ. E. (2010). Yükselti Farkına Göre Sarıçamın (Pinus slyvestris L.) Anotomik ve Kimyasal Bileşiminde Meydana Gelen Değişimler. Doktora Tezi. Bartın Üniversitesi, Fen Bilimleri Enstitüsü, Bartın.

6. Göker, Y, (1983). Reaksiyon Odunu Oluşumunun Ağaç Malzemenin Fiziksel ve Mekanik Özellikleri Üzerine Etkisi Hakkında Araştırmalar, İ.Ü. Orman Fakültesi Yayın No: 3142/339, 1-172 s, İstanbul.

7. Gulsoy S K, Tufek S (2013). Effect of chip mixing ratio of Pinus pinaster and Populus tremula on kraft pulp and paper properties. Industrial \& Engineering Chemistry Research, 52(6), 2304-2308.

8. Gücüş MO, Eroğlu H (2013). Türkiye'de doğal olarak yetişen titrek kavak odununun (Populus tremula L.) lif morfolojisi ve kimyasal yapısının incelenmesi. Ormancılık Dergisi, 9(1): 55-61.

9. Gülsoy SK, Kılıç Pekgözlü A, Aktaş AC (2015). Utilization of the pomegranate tree (Punica granatum L.) in the paper industry Turk J Agric For 39: 295-299 doi:10.3906/tar-1404-105

10. Gülsoy, S K, Eroğlu H. (2011). Influence of Sodium Borohydride on Kraft Pulping of European Black Pine as a Digester Additive, Industrial \& Engineering Chemistry Research, vol. 50, 2441-2444.

11. İstek A, Gonteki E. (2009). Utilization of Sodium Borohydride $\left(\mathrm{NaBH}_{4}\right)$ in Kraft Pulping Process, Journal of Environmental Biology, 30(6): 951-953.

12. ISO 5269-2 (2013). Pulps preparation of laboratory sheets for physical testing. Part 2: Rapid-Köthem method.

13. ISO 5267-1 (2012). Pulps- Determination of Drainability Part I: Schopper Reigler Method

14. Kılıç A, Sarıusta SE, Hafızoğlu H (2010). Sarıçam, Karaçam ve Kızılçam basınç odununun kimyasal yapısı, Bartın Orman Fakültesi Dergisi Cilt 12, Sayı 18, 33-39.

15. Köksal SE, Kılıç Pekgözlü A (2016) Sarıçam, Karaçam ve Kızılçam basınç odununun mikroskobik yapısı, Düzce Üniversitesi Orman Fakültesi Ormancılık Dergisi, 12(1), 72-82.

16. Rowell, R.M., Pettersen, R., Han, J.S., Rowell, J.S., Tshabalala, M.A., 2005. Handbook of Wood Chemistry and Wood Composites. CRC Press, Boca Raton, London, New York.

17. SCAN-CM 15-62 (1962) Viscosity of cellulose in cupriethylenediamine solution (CED)

18. TAPPI T 200 sp-01 (2001) Laboratory beating of pulp (Valley beater method)

19. TAPPI T 222 om-02 (2002) Acid-insoluble lignin in wood and pulp

20. TAPPI T 236 om-99 (1999) Kappa number of pulp.

21. TAPPI T 264 cm-07 (2007) Preparation of wood for chemical analysis.

22. TAPPI T 275 sp-02 (2002) Screening of pulp (Somerville-type equipment)

23. TAPPI T 402 sp-03 (2013) Standard conditioning and testing atmospheres for paper, board, pulp handsheets, and related products.

24. TAPPI $403 \mathrm{om}-02$ (2002). Bursting strength of paper

25. TAPPI 411 om-97 (1997). Thickness (caliper) of paper, paperboard, and combined board

26. TAPPI 412 om-02 (2002). Moisture in pulp, paper and paperboard

27. TAPPI $414 \mathrm{om-98}$ (1998). Internal tearing resistance of paper (Elmendorf-type method)

28. TAPPI T494 om-01 (2001). Tensile Properties of Paper and Paperboard (Using Constant Rate of Elongation Apparatus)

29. TAPPI T519 om-02 (2002). Diffuse Opacity of Paper (d/0 paper backing)

30. TAPPI T525 om-02 (2002). Diffuse Brightness of Pulp (d/0) 
31. Ververis, C., Georghiou, K., Christodoulakis, N., Santas, P., Santas, R. 2004. Fiber dimensions, lignin and cellulose content of various plant materials and their suitability for paper production. Industrial Crops Products 19: 245-254.

32. Wise, L. E. Jahn E. C. (1952). Wood chemistry. Reinhold Publishing Corporation.

33. Yaman, B., Gencer, A. (2005). Trabzon koşullarında yetiştirilen kiwi (Actinidia deliciosa (A. Chev.) C. F. Liang \& A. R. Ferguson)'nin lif morfolojisi. S.D.Ü. Orman Fakültesi Dergisi, A2: 149-155. 